\title{
Severe paraneoplastic hypoglycemia due to a non-islet cell tumor in a patient with an advanced gastrointestinal stromal tumor
}

\author{
Maurizio Alletto, ${ }^{1}$ Antonio Burgio, ${ }^{1}$ Giovanni Fulco, ${ }^{1}$ Giulio Geraci, ${ }^{1}$ Concetta Groppuso, ${ }^{1}$ Gianfranco Gruttadauria, ${ }^{1}$ \\ Elvio Manfrè, ${ }^{1}$ Gianluca Mastrosimone, ${ }^{1}$ Susanna Salvaggio, ${ }^{1}$ Giovanni Urrico, ${ }^{2}$ Federico Vancheri ${ }^{1}$ \\ ${ }^{1}$ Internal Medicine; and ${ }^{2}$ Department of Pathology, S. Elia Hospital, Caltanissetta, Italy
}

\begin{abstract}
Gastrointestinal stromal tumors (GIST) are the most common mesenchymal tumors of the gastrointestinal tract, mainly localized in the stomach. Most GISTs derive from mutations in tyrosine kinase receptors or platelet-derived growth factor receptor- $\alpha$. GISTs are rarely associated with paraneoplastic hypoglycemia caused by a non- $\beta$-cells tumor. This syndrome, defined non-islet cell tumor hypoglycemia (NICTH), arises from excess tumor production of insulin-like growth factor. We describe the case of a 67-year-old female with severe NICTH secondary to an advanced and metastatic GIST.
\end{abstract}

\section{Introduction}

Gastrointestinal stromal tumors (GIST) are the most common mesenchymal malignant tumors of the gastrointestinal tract $(\mathrm{GI})$. Compared to the other tumors,

Correspondence: Federico Vancheri, Internal Medicine, S. Elia Hospital, viale Luigi Monaco, 93100 Caltanissetta, Italy. E-mail: fvanche@tin.it

Key words: Paraneoplastic hypoglycemia; gastrointestinal stromal tumor; non-islet cell tumor hypoglycemia; insulin-like growth factor.

Contributions: MA, AB and GG analyzed and interpreted the clinical and laboratory data. GU made the histopathological examination and immunoistochemical analysis. FV wrote the manuscript. All other authors contributed substantially to the critical revision of the manuscript and approved the final version.

Conflict of interests: the authors declare no potential conflict of interests.

Ethics approval: not required.

Informed consent: the informed consent was signed by the patient on admission and included the use of clinical data for teaching and scientific purposes.

Received for publication: 14 March 2020.

Revision received: 17 April 2020.

Accepted for publication: 17 April 2020.

This work is licensed under a Creative Commons Attribution NonCommercial 4.0 License (CC BY-NC 4.0).

${ }^{\circ}$ Copyright: the Author(s), 2020

Licensee PAGEPress, Italy

Italian Journal of Medicine 2020; 14:167-171

doi:10.4081/itjm.2020.1276 they are rare, accounting for 1-2\% of all gastrointestinal neoplasms. ${ }^{1}$ GIST can develop anywhere in the GI tract, most commonly in the stomach $(60 \%)$ and the small intestine (30\%), and less frequently in the colon, rectum, and esophagus. ${ }^{2-6} \mathrm{~A}$ few cases $(<5 \%)$ are found in different sites within the abdominal cavity, especially in the mesentery, omentum, and retroperitoneum. ${ }^{7}$ The reported incidence of GIST is about 10 cases per million inhabitants/year in Europe. ${ }^{8,9}$ Clinical manifestations depend on the tumor location, size, and growth pattern. About one out of four GISTs are asymptomatic and incidentally discovered during the endoscopic examination or abdominal computer tomography (CT) scan performed for other disorders. Symptomatic patients present with weight loss, abdominal pain, gastrointestinal bleeding, or bowel perforation. ${ }^{1,10,11}$ At the time of diagnosis about the half of patients have advanced disease with metastases. ${ }^{12}$

Non-islet cell tumor hypoglycemia (NICTH) is a rare paraneoplastic syndrome caused by non- $\beta$-cells tumors. The clinical features are recurrent fasting hypoglycemia, associated with normal or decreased levels of insulin and insulin-like growth factor (IGF1), and elevated insulin-like growth factor-2 (IGF2). ${ }^{13-15}$ NICTH has been associated with mesenchymal and epithelial tumors including hepatocellular carcinoma, lymphoma, fibrosarcoma, nerve sheath tumors, hemangiopericytoma, and thyroid carcinoma. ${ }^{15-20}$ The association of NICTH with GIST is rare, and only fifteen cases have been identified in the review of the literature covering the past 16 years. ${ }^{21-25}$ However, before the diagnostic immunohistochemical analysis in the ' 80 s, GISTs were often misdiagnosed as abdominal leiomyoma or leiomyosarcoma, and many of those associated with NICTH showed histological features which could represent GISTs. ${ }^{26,27}$

We present a case of severe NICTH secondary to an advanced and metastatic GIST. 


\section{Case Report}

A 67-year-old female patient was admitted to the Internal Medicine ward complaining of diffuse pain in the upper abdomen that had lasted three weeks, not associated with meals. She reported an undetermined weight loss during the previous month despite the usual food intake. The patient had a long history of hypertension well controlled with medications and positive family history for colon and gastric cancer (parents).

On admission, her vital signs were within normal limits. The physical examination revealed abdominal tenderness with a palpable mass in the right upper quadrant. Laboratory tests showed normal values of fasting glycemia, hemoglobin, white blood cells count, renal and adrenal function, liver enzymes, fibrinogen, prothrombin time, and thyroid function tests. Increased values of C-reactive protein (104, normal up to 5), and cancer antigen CA 125 (291, normal up to 35 ) and NSE (22.5, normal up to 16 ) were also observed.

An abdominal ultrasound, contrast-enhanced CT scan, and magnetic resonance imaging of the abdomen revealed multiple lobulated peritoneal and mesenteric masses of varying sizes, with necrotic areas (Figure 1). There were also multiple sub-diaphragmatic and peri-hepatic lesions measuring from few millimeters to $3-4 \mathrm{~cm}$, the largest $13 \times 8 \mathrm{~cm}$, extending in the Morison's pouch. The stomach wall was thickened in the cardia, fundus, and great curvature regions. Multiple lobulated masses with the same characteristics were observed in the lower abdomen, close to the small bowel, without signs of obstruction. A scan of the thorax showed moderate bilateral pleural effusion and small non-calcified soft tissue nodules in the breast. The upper gastrointestinal tract endoscopy, and colonoscopy did not show any pathological finding.

On the fourth day, the patient developed fasting autonomic and neuroglycopenic symptoms and signs consistent with severe hypoglycemia, with blood glucose lower than $1.1 \mathrm{mmol} / \mathrm{L}(20 \mathrm{mg} / \mathrm{dL})$ and rapid resolution after glucose infusion. Further episodes of hypoglycemia occurred in the following days requiring treatment with continuous intravenous infusion of glucose, corticosteroids, and glucagon. During these episodes, the patient remained fully conscious and awake, even when blood glucose fell below 1.6 $\mathrm{mmol} / \mathrm{L}(30 \mathrm{mg} / \mathrm{dL})$.

Insulinoma or NICTH were suspected. An endocrine laboratory test showed low values of insulin (0.4 microUI/mL, normal 2.6-25), C-peptide (0.1 $\mathrm{ng} / \mathrm{mL}$, normal 1.1-4.4), growth hormone $(0.12$ $\mathrm{ng} / \mathrm{mL}$, normal 0-10) and insulin-like growth factor-1 (IGF1, $86 \mathrm{ng} / \mathrm{mL}$, normal for age 81-200).

An ultrasound-guided fine-needle biopsy of the largest abdominal mass was performed. The biopsy specimen was stained with hematoxylin and eosin for microscopic examination.

Histopathology showed spindle-shaped and epithelioid cells, growing in the form of fascicles, palisades, and whorls, including large cells with hyperchromatic nuclei, marked diffuse cellularity and nuclear palisading with 1-2 mitoses at 10x magnification (Figure 2).

Immunohistochemical analysis was carried out using monoclonal antibodies on an automated staining system (Benchmark Ultra, Roche Ventana). Neurallike differentiation was shown by the expression of
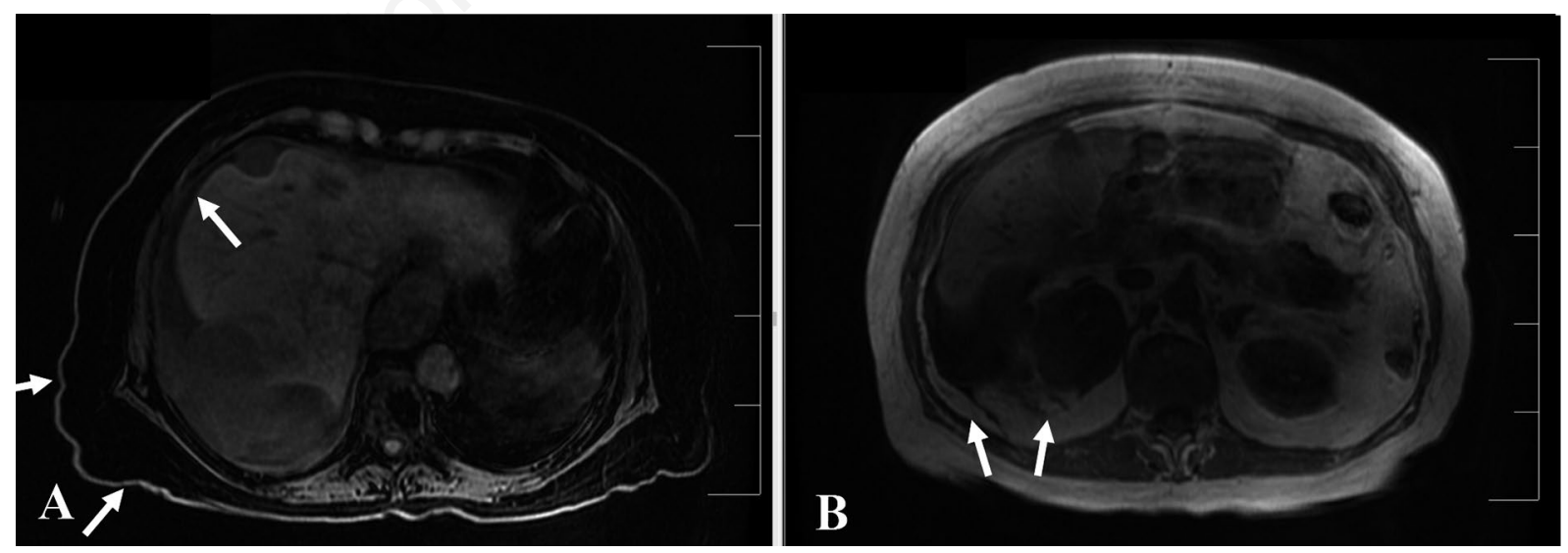

Figure 1. Non-contrast magnetic resonance images acquired using the Dixon technique. (A) axial water only sequence showing multiple soft tissue peritoneal localization adjacent to the anterior, lateral, and posterior margin of the right lobe of the liver (arrows). (B) on a more caudal level, axial in-phase sequence depicts peritoneal localization adjacent to the posterior and medial margin of the VI segment of the liver and a retroperitoneal localization adjacent to the superior pole of the right kidney (arrows). In the same examination, contrast enhancement and restricted diffusion within the walls of the body of the stomach were noticed (not shown). 
neuron-specific enolase (MRQ55 clone) and Vimentin (V9 clone). Stem-cell growth factor receptor (CD117) and receptor tyrosine kinase (c-KIT) were positive in $60 \%$ of the neoplastic cellular population (Figure 3). These findings were compatible with the histological diagnosis of GIST.

Based on the pathology findings, treatment with the tyrosine kinase inhibitor imatinib, $400 \mathrm{mg} /$ day, was started. One week later, despite intensive medical support, the patient became comatose and died two days later.

\section{Discussion}

As a general rule, tumor-associated hypoglycemia may be due to a tumor producing an excess of insulin, such as pancreatic insulinoma, or due to destruction of the liver and adrenal glands by massive tumor infiltration or the production of substances interfering with glucose metabolism, such as insulin-receptor antibodies or secretion of IGF1. However, in the setting of decreased insulin and IGF1 levels with normal hepatic and adrenal function, the tumor-associated hypoglycemia suggests the diagnosis of paraneoplastic NICTH, ruling out insulinoma and IGF1-producing tumors. Hypoglycemia due to NICTH is thought to derive from tumor secretion of IGF2 associated with a more significant proportion of the incompletely processed high-molecular-weight precursor (pro-IGF2 or big IGF2). In healthy individuals big IGF2 account for about $20 \%$ of the total IGF2, whereas in patients with NICTH, $80 \%$ of IGF2 are circulating as big IGF $2 .^{28}$ Both IGF1 and IGF2 are mainly produced by the liver and share structural similarities with insulin..$^{29}$ Although their concentration is about 100 times the

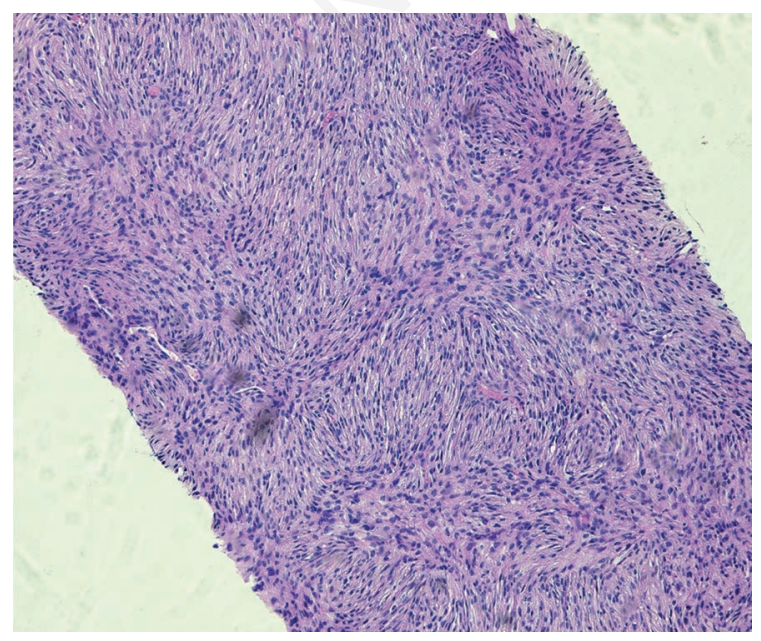

Figure 2. Hematoxylin and eosin stain showing multiple palisade cells indicative of neural differentiation. one of insulin, they are almost entirely bound to IGFbinding protein-3 (IGFBP3) and an acid-labile subunit, resulting in a biologically inactive ternary complex. ${ }^{30,31}$ Like the other hormones, the free hormone mediates their physiological activity, hence IGFs do not induce significant hypoglycemia. Tumor-derived big IGF2 has high affinity for insulin receptors but binds poorly to its binding protein because of its excessive molecular weight, thus remaining free unbound or forming a smaller binary complex. ${ }^{32}$ Unlike a ternary complex, the small binary complex and the free form may cross through the capillary wall reaching the cells' surface and activating the insulin receptors. ${ }^{33,34}$ Big IGF2 is about four times more biologically active than IGF2. This results in persistent insulin-like activity leading to hypoglycemia due to inhibition of glycogenolysis and gluconeogenesis, decreased lipolysis, and increased peripheral glucose utilization. Both hypoglycemia and a direct inhibitory effect of big IGF2 at pancreas level decrease insulin secretion. This results in the up-regulation of insulin receptors, causing increased insulin sensitivity. In addition, big IGF2 suppresses the secretion of pituitary growth hormone $(\mathrm{GH})$, thus decreasing the synthesis of IGF1 and IGFBP3. ${ }^{31,35}$

In the present patient, IGF2 and big IGF2 were not measured because diagnostic tests are not widely available. Furthermore, while the tumor secretion of big IGF2 is increased in the majority of patients with NICTH, the concentration of IGF2 may be increased or even normal. ${ }^{21,30,36}$ Therefore, measuring IGF2 levels does not provide meaningful results in the diagnosis of NICTH.

The other laboratory tests, such as the reduction of both insulin and IGF1, along with reduced C-peptide and GH, support the hypothesis that big IGF2 was re-

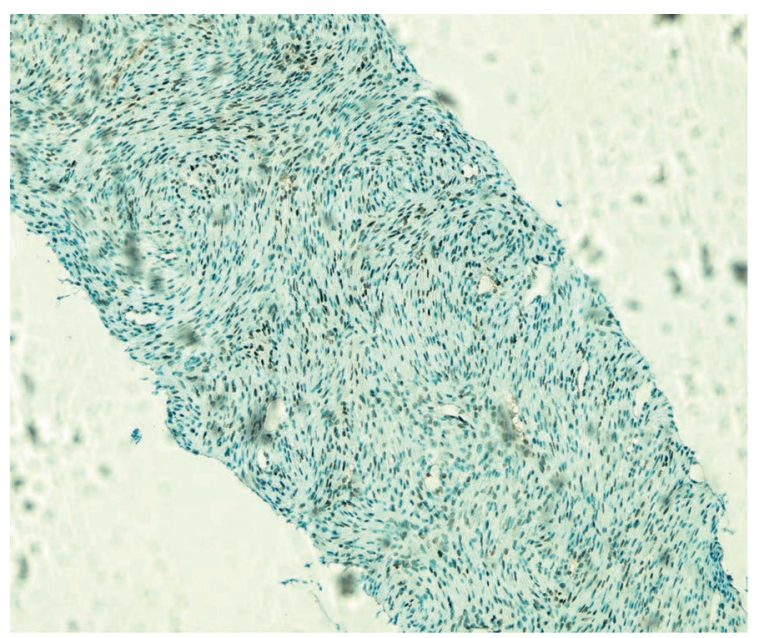

Figure 3. Immunohistochemical analysis showing CD117/c-KIT immunoreactivity. 
sponsible for the sustained hypoglycemia in this patient.

In some cases, the GIST-associated hypoglycemia is not caused by big IGF2 but may be attributed to the metabolic effects of neoplastic malnutrition, hepatic and renal dysfunction, and sepsis. ${ }^{37}$ Our patient had a normal hepatic and renal function and no sign of infection or malnutrition.

In the present patient the tumor was detected before the occurrence of hypoglycemia, which is the presentation in about the half of patients, whereas hypoglycemia is the onset of disease in the others. ${ }^{15} \mathrm{Al}-$ though the paraneoplastic manifestation of NICTH in GIST is rare, when it occurs, the tumor is advanced or metastatic. $^{38}$

Most GISTs derive from the interstitial cells of Cajal, which are pacemaker cells involved in the contractile activity of the GI tract..$^{39,40}$ The pathology of GISTs consists of three morphological patterns, including spindle cell (70\%), epithelioid (20\%), and the mixed type (10\%). These features are not specific to GIST but may overlap with other tumors of the GI tract. Because the cells of Cajal are modified smooth muscle cells with a neural function for peristaltic contraction, the microscopic and ultrastructural appearance of GIST may have mixed features of smooth muscle and nerve sheath cells. Therefore, immunohistochemical stains are used to confirm a suspected diagnosis. GIST should be considered in the differential diagnosis of mesenchymal or epithelioid tumors involving the liver, pancreas, and pelvic cavity. In this specific case, GIST was thought to derive from the stomach and histologically comprised spindle-shaped and epithelioid cells positive for KIT.

Immunohistochemistry studies have demonstrated that the receptor tyrosine kinase KIT, also known as stem-cell growth factor receptor or CD117, is essential for the development of interstitial cells of Cajal. ${ }^{41}$ More than $95 \%$ of GISTs are positive for KIT (CD117) protein staining. ${ }^{38,42}$ About $90 \%$ of GISTs have mutations of KIT, and a smaller proportion have a mutation of platelet-derived growth factor receptor$\alpha$ (PDGFRA), a close homolog of KIT. These mutations result in oncogenic kinase activation that can cause uncontrolled cell proliferation leading to a stromal tumor. ${ }^{6,8,43,44}$ Hence, the expression of KIT or PDGFRA is a crucial diagnostic marker for GIST. However, a small subset of GISTs does not have detectable KIT or PGDFRA mutation.

The treatment of localized disease is based on surgical removal of the tumor mass. Resection is not always possible in extensive metastatic disease. GISTs are resistant to conventional chemotherapy and only slightly sensitive to radiotherapy. However, a class of tyrosine kinase inhibitors, such as imatinib and sunitinib, and regorafenib as second-line medication, was introduced in the early 2000s and is currently used to treat metastatic disease and in the adjuvant treatment of KIT-positive tumors. ${ }^{6,8,45}$

\section{Conclusions}

Although the association of NICTH with GIST is rare, the occurrence of sustained hypoglycemia with low levels of insulin and IGF1 can be a paraneoplastic manifestation of an underlying tumor, especially a GIST. The identification of GIST has considerable clinical relevance because KIT-selective tyrosine kinase inhibitors have been proved effective in the tumor adjuvant treatment.

\section{References}

1. Parab TM, DeRogatis MJ, Boaz AM, et al. Gastrointestinal stromal tumors: a comprehensive review. J Gastroint Oncol 2019;10:144-54.

2. Sanchez-Hidalgo JM, Duran-Martinez M, MoleroPayan R, et al. Gastrointestinal stromal tumors: A multidisciplinary challenge. World J Gastroenterol 2018;24: 1925-41.

3. Tsikrikas S, Manolakopoulos S, Deutsch M, et al. Unusual combination of paraneoplastic manifestations in a patient with metastatic gastrointestinal stromal tumor (GIST). Scand J Gastroenterol 2008;43:1012-5.

4. Reddy P, Boci K, Charbonneau C. The epidemiologic, health-related quality of life, and economic burden of gastrointestinal stromal tumours. J Clin Pharm Ther 2007;32:557-65.

5. Søreide K, Sandvik OM, Søreide JA, et al. Global epidemiology of gastrointestinal stromal tumours (GIST): A systematic review of population-based cohort studies. Cancer Epidemiol 2016;40:39-46.

6. Joensuu H, Hohenberger P, Corless CL. Gastrointestinal stromal tumour. Lancet 2013;382:973-83.

7. Miettinen MM, Monihan JJ, Sarlomo-Rikala JM, et al. Gastrointestinal stromal tumors/smooth muscle tumors (GISTs) primary in the omentum and mesentery: clinicopathologic and immunohistochemical study of 26 Cases. Am J Surg Pathol 1999;23:1109-18.

8. Zhao X, Yue C. Gastrointestinal stromal tumor. J Gastroint Oncol 2012;3:189.

9. Rubin BP, Heinrich MC, Corless CL. Gastrointestinal stromal tumour. Lancet 2007;369:1731-41.

10. Menge F, Jakob J, Kasper B, et al. Clinical presentation of gastrointestinal stromal tumors. Visceral Med 2018;34:335-40.

11. Cavallini M, Romiti A, Pilozzi E, et al. Gastrointestinal stromal tumors: correlation between symptoms at presentation, tumor location and prognostic factors in 47 consecutive patients. World J Surg Oncol 2011;9:13.

12. Dematteo PR, Lewis JJ, Leung SD, et al. Two hundred gastrointestinal stromal tumors: recurrence patterns and prognostic factors for survival. Ann Surg 2000; 231:51-8.

13. Rikhof B, van Doorn J, Suurmeijer AJH, et al. Insulinlike growth factors and insulin-like growth factor-binding proteins in relation to disease status and incidence 
of hypoglycaemia in patients with a gastrointestinal stromal tumour. Ann Oncol 2009;20:1582-8.

14. Iglesias P, Diez JJ. Management of Endocrine Disease. A clinical update on tumor-induced hypoglycemia. Eur J Endocrinol 2014;170:R147-R57.

15. Fukuda I, Hizuka N, Ishikawa Y, et al. Clinical features of insulin-like growth factor-II producing non-islet-cell tumor hypoglycemia. Growth Horm IGF Res 2006;16: 211-6.

16. De Groot JWB, Rikhof B, Van Doorn J, et al. Non-islet cell tumour-induced hypoglycaemia: a review of the literature including two new cases. Endocr-Relat Cancer 2007;14:979-93.

17. Forde JJ, Ewelukwa O, Brar T, Cabrera R. Intractable fasting hypoglycemia as a manifestation of hepatocellular carcinoma. Case Rep Hepatol 2017:7465025.

18. Kitada M, Yasuda S, Takahashi N, et al. Non-islet cell tumor hypoglycemia caused by intrathoracic solitary fibrous tumor: a case report. J Cardiothor Surg 2016;11:49.

19. Morioka T, Ohba K, Morita H, et al. Non-islet cell tumor-induced hypoglycemia associated with macronodular pulmonary metastases from poorly differentiated thyroid carcinoma. Thyroid 2014;24:395-9.

20. Gullo D, Sciacca L, Parrinello G, et al. Treatment of hemangiopericytoma-induced hypoglycemia with growth hormone and corticosteroids. J Clin Endocrinol Metab 1999;84:1758-9.

21. Hirai H, Ogata E, Ohki S, et al. Hypoglycemia associated with a gastrointestinal stromal tumor producing high-molecular-weight insulin growth factor ii: a case report and literature review. Intern Med 2016;55:1309-14.

22. Wilson JM, Ginsberg J, Cutts K, Urban S. A case of nonislet cell tumor hypoglycemia (NICTH) associated with gastrointestinal stromal tumor (GIST). Am J Case Rep 2017;18:984-8.

23. Saeed Z, Taleb S, Evans-Molina C. A case of extragastrointestinal stromal tumor complicated by severe hypoglycemia: a unique presentation of a rare tumor. BMC Cancer 2016;16:930.

24. Dimitriadis GK, Gopalakrishnan K, Rao R, et al. Severe paraneoplastic hypoglycemia secondary to a gastrointestinal stromal tumour masquerading as a stroke. Endocrinol Diabet Metab Case Rep 2015;2015:150062.

25. Hamberg P, de Jong FA, Boonstra JG, et al. Non-isletcell tumor induced hypoglycemia in patients with advanced gastrointestinal stromal tumor possibly worsened by imatinib. J Clin Oncol 2006;24:e30-e1.

26. Anderson N, Lokich JJ. Mesenchymal tumors associated with hypoglycemia: Case report and review of the literature. Cancer 1979;44:785-90.

27. Mazur TM, Clark BH. Gastric stromal tumors Reappraisal of histogenesis. Am J Surg Pathol 1983;7:507-20.

28. Miraki-Moud F, Grossman AB, Besser M, et al. A rapid method for analyzing serum pro-insulin-like growth factor-ii in patients with non-islet cell tumor hypoglycemia. J Clin Endocrinol Metab 2005;90:3819-23.
29. Lewitt MS. Role of the insulin-like growth factors in the endocrine control of glucose homeostasis. Diabet Res Clin Pract 1994;23:3-15.

30. Dynkevich Y, Rother KI, Whitford I, et al. Tumors, IGF2, and hypoglycemia: insights from the clinic, the laboratory, and the historical archive. Endocr Rev 2013;34:798-826.

31. Davda R, Seddon BM. Mechanisms and management of non-islet cell tumour hypoglycaemia in gastrointestinal stromal tumour: case report and a review of published studies. Clin Oncol 2007;19:265-8.

32. Baxter RC, Daughaday WH. Impaired formation of the ternary insulin-like growth factor-binding protein complex in patients with hypoglycemia due to nonislet cell tumors*. J Clin Endocrinol Metab 1991;73:696-702.

33. Bodnar TW, Acevedo MJ, Pietropaolo M. Management of non-islet-cell tumor hypoglycemia: a clinical review. J Clin Endocrinol Metab 2014;99:713-22.

34. Ko AH, Bergsland EK, Lee GA. Case report: tumor-associated hypoglycemia from metastatic colorectal adenocarcinoma: case report and review of the literature. Digest Dis Sci 2003;48:192-6.

35. Le Roith D. Insulin-like growth factors. N Engl J Med 1997;336:633-40.

36. Hizuka N, Fukuda I, Takano K, et al. Serum insulin-like growth factor ii in 44 patients with non-islet cell tumor hypoglycemia. Endocr J 1998;45:S61-S5.

37. Singh R, Grey A, Miller M, et al. Non-hyperinsulinemic hypoglycemia in a patient with a gastrointestinal stromal tumor. Eur J Intern Med 2006;17:127-9.

38. Escobar GA, Robinson WA, Nydam TL, et al. Severe paraneoplastic hypoglycemia in a patient with a gastrointestinal stromal tumor with an exon 9 mutation: a case report. BMC Cancer 2007;7:13.

39. Hirota S. Differential diagnosis of gastrointestinal stromal tumor by histopathology and immunohistochemistry. Transl Gastroenterol Hepatol 2018;3:27-.

40. Huizinga J, Chen J, Mikkelsen H, et al. Interstitial cells of Cajal, from structure to function. Front Neurosci 2013;7.

41. Hulzinga JD, Thuneberg L, Klüppel M, et al. W/kit gene required for interstitial cells of Cajal and for intestinal pacemaker activity. Nature 1995;373:347-9.

42. Guiteau J, Fanucchi M, Folpe A, et al. Hypoglycemia in the Setting of Advanced Gastrointestinal Stromal Tumor. Am Surg 2006;72:1225-30.

43. Corless CL, Barnett CM, Heinrich MC. Gastrointestinal stromal tumours: origin and molecular oncology. Nature Reviews Cancer 2011;11:865-78.

44. Hirota S, Isozaki K, Moriyama Y, et al. Gain-of-function mutations of c-kit in human gastrointestinal stromal tumors. Science 1998;279:577-80.

45. Mantese G. Gastrointestinal stromal tumor: epidemiology, diagnosis, and treatment. Curr Opin Gastroenterol 2019;35:555-9. 